\title{
Effect of the duration of malnutrition and of nutritional rehabilitation on blood glucose homeostasis and pancreatic hormones in rats
}

\author{
BY JEAN-MARC DOLLET ${ }^{1,2 *}$, BERNARD BECK ${ }^{1}$ \\ AND JEAN-PIERRE MAX ${ }^{1}$ \\ ${ }^{1}$ Unité de Recherches sur les Mécanismes de Régulation du Comportement Alimentaire, \\ INSERM U 308, 38 rue Lionnois, 54000 Nancy, France \\ ${ }^{2}$ Unité de Recherches sur la Nutrition et l'Alimentation INSERM U 1, Hôpital Bichat, \\ 170 bvd Ney, 75877 Paris Cedex 18, France
}

(Received 12 August 1987 - Accepted 19 February 1988)

\begin{abstract}
1. To study the efficiency of rehabilitation after different periods of protein-energy malnutrition, we used as a model preweaning malnourished rats. After weaning, male Wistar rats were fed on a protein-deficient diet $(50 \mathrm{~g}$ casein $/ \mathrm{kg}$ ) ad lib. for the whole study (DR group) or rehabilitated with normal diet ( $180 \mathrm{~g}$ casein $/ \mathrm{kg} ; \mathrm{RR}$ group) from weaning, week 0 , or weeks $1,3,5,8$ and 16 thereafter.

2. Twelve animals from the DR group were killed at the beginning of each rehabilitation period. The twelve rehabilitated rats were killed after 2 weeks. Body-weight and epididymal adipose tissue weight, blood glucose, plasma immunoreactive insulin (IRI) and immunoreactive glucagon (IRG), and pancreatic contents of IRI and IRG were determined.

3. Food intake of RR rats rose significantly except during the last period where body-weight increased less than that during the previous periods. Fat-pad weights increased in the same manner in DR and RR groups.

4. Blood glucose fell and plasma IRG rose significantly without any change in plasma IRI after each rehabilitation period, except during the last period where blood glucose concentrations became stable. Pancreatic IRG and IRI showed the same type of response to those of the plasma.

5. All short-term rehabilitation periods were similarly efficient at producing catch-up growth. High insulin sensitivity of target cells was responsible for good recovery except after long-term malnutrition.
\end{abstract}

One of the most crucial needs following protein -energy malnutrition (PEM) in man is the recovery of various tissue functions by nutritional rehabilitation. This is particularly important in developing countries where between 27 and $51 \%$ of the children are undernourished (Haaga et al. 1985). It was shown that weight gain after rehabilitation is positively correlated with energy intake and plasma insulin (Robinson et al. 1980). The more severe the extent of malnutrition before rehabilitation, the less likely that blood glucose and insulin would be normalized (Robinson \& Picou, 1977).

Children in developing countries may not only be submitted to postweaning but also to preweaning malnutrition: maternal malnutrition is responsible for low-birth weight, a sign of nutritional deficiency of the fetus (Tafari et al. 1980), and impaired growth may continue during lactation with many other consequences (Edozien et al. 1976).

As we have previously shown (Dollet et al. 1987), newborn rats undernourished during pregnancy and lactation provide a good model to study glycoregulation of mildly undernourished children: at weaning, rats are already well adapted to PEM. Long-term rehabilitation leads to a quite-normal glucose status except insulin resistance which appears as a consequence of chronic malnutrition. The levels of recovery of function of various organs are different according to the duration of previous malnutrition (Rozovski et al. 1982; Warren \& Bedi, 1985).

\footnotetext{
* Present address: Service de Médecine A, CHG St Charles, 88100 Saint-Dié, France.
} 
Table 1. Composition of the control and deficient diets $(\mathrm{g} / \mathrm{kg})$

\begin{tabular}{lccc}
\hline Ingredient & Control & Protein-deficient \\
\hline Casein & 180 & 50 \\
Maize starch & 670 & 800 \\
Peanut oil & 80 & 80 \\
Salt mixture* & 40 & 40 \\
Vitamins* & 10 & 10 \\
Cellulose & 20 & 20 \\
Methionine & - & 2 \\
\hline
\end{tabular}

* Detailed composition given by Dollet et al. (1985).

The aim of the present study was to investigate the recovery of body-weight in relation to glucose homeostasis, changes in insulin and glucagon concentrations and duration of malnutrition.

\section{MATERIAL AND METHODS}

Animals and diet

Animals were supplied from the inbred colony at our laboratory. From a total of 450 male Wistar rats, born to protein-deprived mothers, 144 animals of the closest body-weight at weaning (day 24) were selected. The deprived mothers were fed on a $75 \mathrm{~g}$ casein $/ \mathrm{kg}$ diet (previously described by Beck et al. 1983) from $15 \mathrm{~d}$ before mating until the end of the suckling period. At weaning (week 0 ) twenty-four rats were randomly chosen; twelve were killed by decapitation (DR0; deprived rats at week 0 ), the other twelve being fed on a $180 \mathrm{~g}$ casein $/ \mathrm{kg}$ diet for 2 weeks before killing (RR2; rehabilitated rats at week $0+2$ ). The remaining rats were randomly distributed into five groups of twenty-four rats; all these rats were fed on a $50 \mathrm{~g}$ casein $/ \mathrm{kg}$ diet. After $1,3,5,8$ and 16 weeks, one of these groups was chosen and, as at week 0 , twelve rats were killed (DR1, DR3 ...DR16) and the other twelve rehabilitated with a $180 \mathrm{~g}$ casein $/ \mathrm{kg}$ diet for 2 weeks before killing (RR3, RR5 ... RR18).

The composition of the two diets is given in Table 1 ; they were isoenergetic since maize starch replaced casein in the protein-deficient diet. Both diets were stored at $5^{\circ}$. Food and tap water were given ad lib. Food intake was measured twice weekly throughout the study. The animals were housed in individual wired cages in an air-conditioned room with $12 \mathrm{~h}$ dark-12 h light cycle, light starting at 07.00 hours.

\section{Sampling and assay}

The animals were weighed on the day before death. After a $16 \mathrm{~h}$ fasting period, they were decapitated between 09.00 and 11.00 hours. Arterio-venous blood was collected in a test tube containing EDTA (Prolabo, Paris; $1 \mathrm{mg} / \mathrm{ml}$ ) and aprotinin (INIPROL ${ }^{\circledR}$ Choay, Paris; $4000 \mathrm{IU} / \mathrm{ml}$ ). From week 0 to week 8 , the plasma of two or three DR rats per group were pooled to obtain a sufficient quantity for all assays; RR rats gave enough plasma and were not pooled. Plasma was divided into portions and stored at $-20^{\circ}$ until blood glucose, immunoreactive insulin (IRI) and immunoreactive glucagon (IRG) were assayed. Immediately after death, the whole pancreas of six randomly-selected rats from each group was carefully dissected, weighed and rapidly frozen in liquid nitrogen in a test tube containing aprotinin (200000 IU). The pancreases were stored at $-20^{\circ}$ until insulin and glucagon were extracted. Extraction and assay methods have been previously described (Dollet et al. 1985). Epididymal adipose tissues were excised, pooled and weighed. 


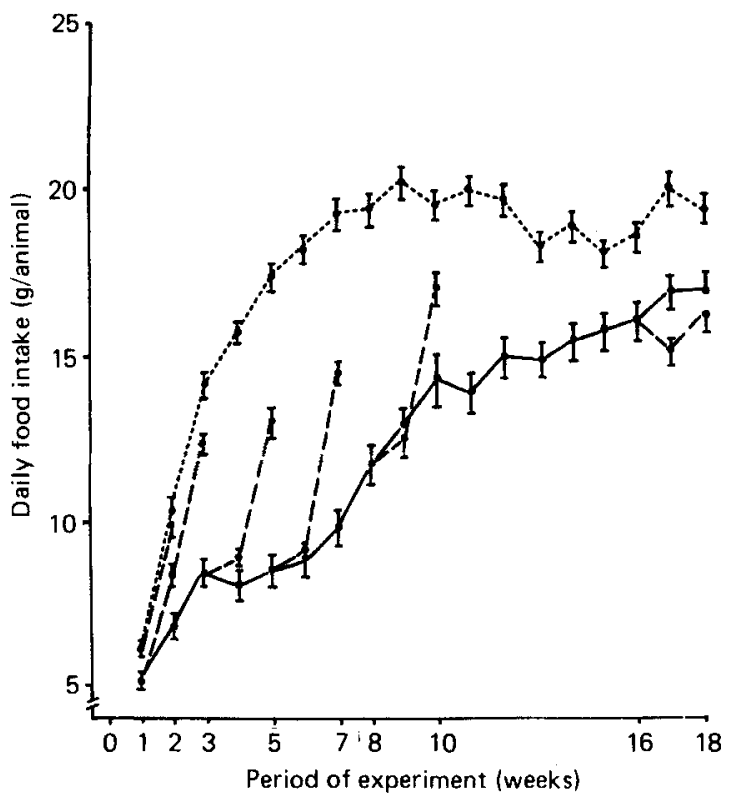

Fig. 1. Daily food intake ( $\mathrm{g} /$ animal) of rats born from malnourished mothers. $50 \mathrm{~g}$ casein $/ \mathrm{kg}$ diet $\mathrm{ad}$ lib. after weaning; (-) , rats rehabilitated with $180 \mathrm{~g}$ casein $/ \mathrm{kg}$ diet $a d l i b$. for 2 weeks; (-... ), rats rehabilitated from weaning (reproduced from Dollet et al. 1987).

\section{Statistical methods}

Results are expressed as means with their standard errors. They were compared using Student's $t$ test. A probability of $P<0.05$ was considered significant.

\section{RESULTS}

Mean food intakes and body-weights are shown in Figs. 1 and 2 respectively. They show values for groups DR and $\mathrm{RR}$ with corresponding values for a group of long-term rehabilitated rats ( $180 \mathrm{~g}$ casein $/ \mathrm{kg}$ diet from weaning); these results have been previously partly reported (Beck et al. 1983). Food intake rose immediately in the 1st week only during the first two periods of rehabilitation. During the 2 nd week of each rehabilitation period, there was a significant increase with an identical slope, except for the last period (weeks 16-18) where food intakes did not recover. Body-weights of group RR showed the same responses during the first 5 periods: a significant and constant rise of about $45 \mathrm{~g} /$ week. During the last rehabilitation period, there was no significant increase during the 1 st week but the difference was significant after 2 weeks.

Fig. 3 shows the increase in epididymal adipose tissue weight: at weaning tissue weights were very small $(56 \mathrm{mg})$. In DR rats the tissue grew very slowly. A 2-week period of rehabilitation did not allow the RR group to show a significant increase in weight at any time.

Changes in insulin concentrations are shown in Fig. 4. Plasma IRI (Fig. 4(a)) of RR rats did not vary significantly after any period of nutritional rehabilitation. The only significant changes in pancreatic IRI content (Fig. $4(b)$ ) occurred during the first two periods; that of $R R$ rats fell, but when we compared the following values: RR2 with DR1, RR2 with DR3 and RR3 with DR3, there were no significant differences. 


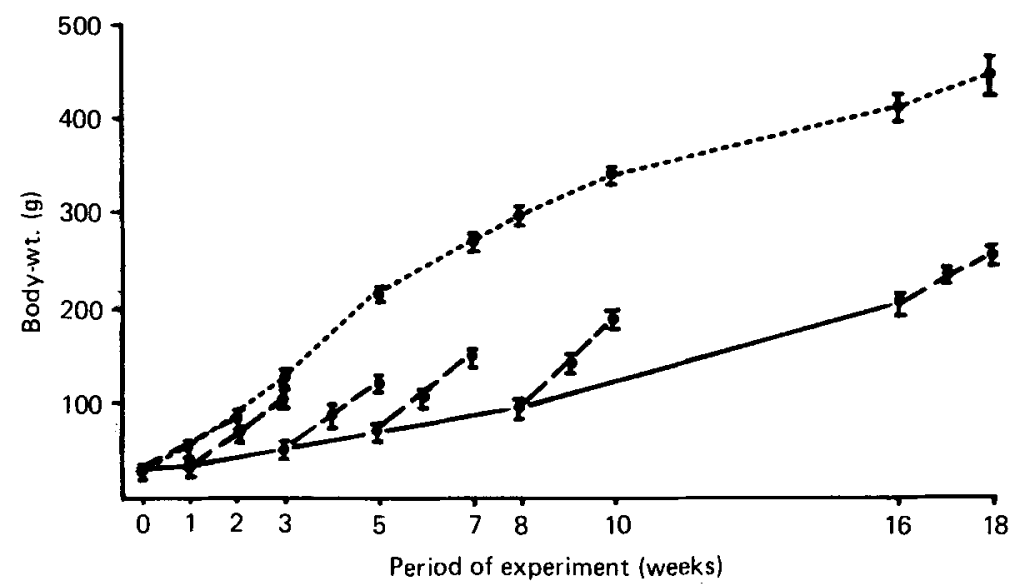

Fig. 2. Body-weight curves of rats born from malnourished mothers. ( -9 ), Rats fed on $50 \mathrm{~g}$ casein $/ \mathrm{kg}$ diet ad lib. after weaning; (-- ), rats rehabilitated with $180 \mathrm{~g}$ casein $/ \mathrm{kg}$ diet ad lib. for 2 weeks; (---), rats rehabilitated from weaning (reproduced from Dollet et al. 1987).

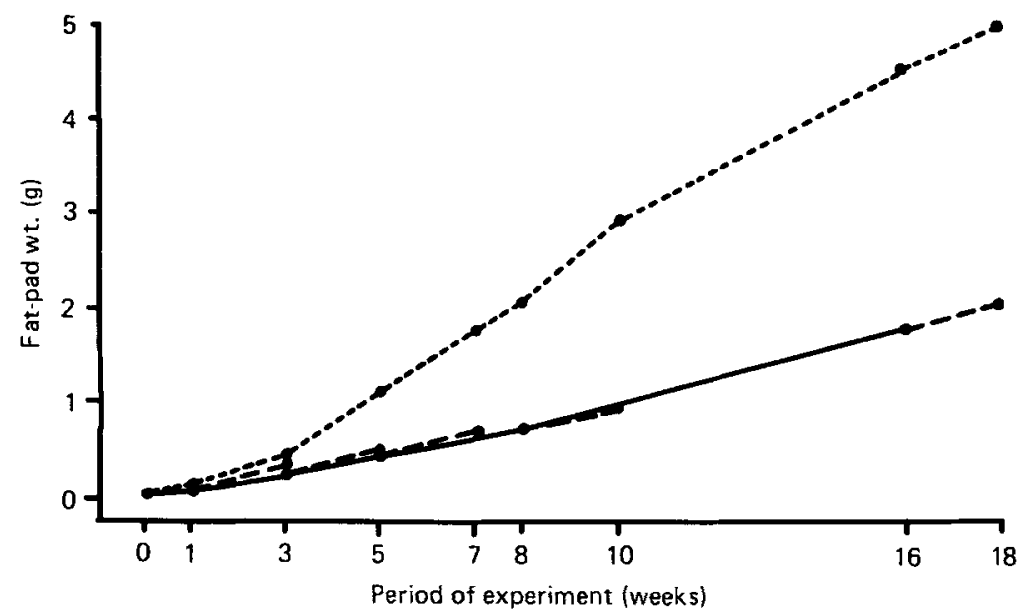

Fig. 3. Epididymal-fat-pad-weight curves of rats born from malnourished mothers. (- Rats fed on $50 \mathrm{~g}$ casein $/ \mathrm{kg}$ diet $a d$ lib. after weaning; (--O), rats rehabilitated with $180 \mathrm{~g}$ casein $/ \mathrm{kg}$ diet $a d$ lib. for 2 weeks; (-.--) rats rehabilitated from weaning.

Fig. 5 shows the response of glucagon to nutritional rehabilitation. Plasma IRG (Fig. $5(a)$ ) always rose after 2 weeks of rehabilitation, except during the third period (weeks 3-5). During the first, second and fourth periods, this increase was by a similar proportion, but at the end of the study (weeks $8-10$ and 16-18) the differences between DR and RR rats were less and less marked, although still significant. Fig. 5(b) shows that pancreatic IRG content of the RR group significantly dropped during the first period of rehabilitation (weeks 0-2), but not more than that for DR rats since there was no significant difference between values for RR2 and DR1 rats. In the second period (weeks 1-3), pancreatic IRG content fell again but to a lesser extent than before. 

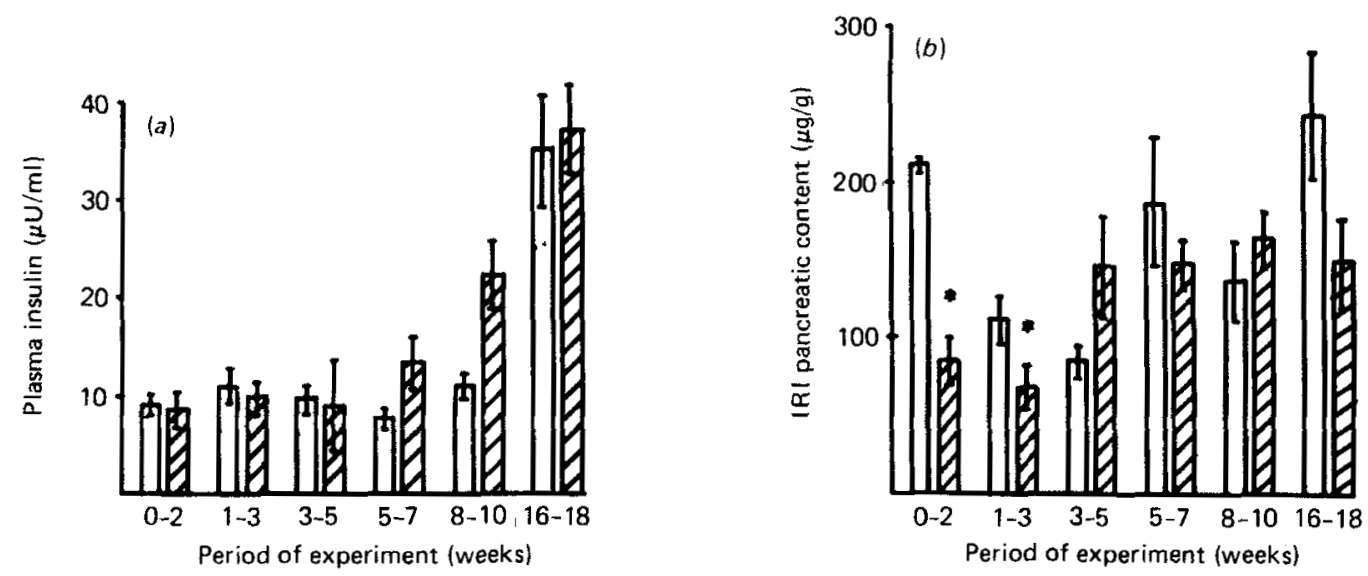

Fig. 4. Changes in (a), plasma insulin and $(b)$, pancreatic immunoreactive insulin (IRI) of rats born from malnourished mothers and either fed on a $50 \mathrm{~g}$ casein $/ \mathrm{kg}$ diet ad lib. after weaning $(\square)$ or rehabilitated with $180 \mathrm{~g}$ casein $/ \mathrm{kg}$ diet ad lib. for 2 weeks ( $\square$ ). Mean values and standard deviations represented by vertical bars. $* P<0.05$.
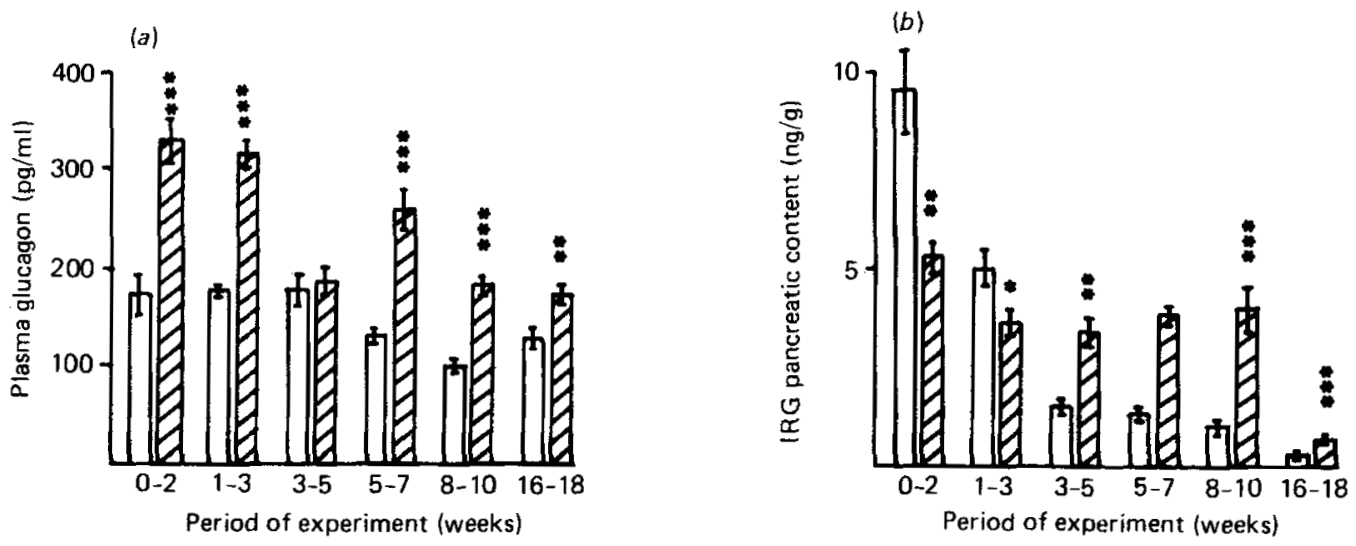

Fig. 5. Changes in (a), plasma glucagon and (b), pancreatic immunoreactive glucagon (IRG) of rats born from malnourished mothers and either fed on $50 \mathrm{~g}$ casein $/ \mathrm{kg}$ diet ad lib. after weaning ( $\square$ ) or rehabilitated with $180 \mathrm{~g}$ casein $/ \mathrm{kg}$ diet $a d l i b$. for 2 weeks $(囚)$. Mean values and standard deviations represented by vertical bars. ${ }^{*} P<0.05,{ }^{* *} P<0.01,{ }^{* *} P<0.001$.

Fig. 6 indicates the consequences of those hormonal changes on glucose homeostasis. Blood glucose (Fig. 6(a)) fell during the first five periods but the differences were only significant between weeks 0-2 and 5-7. During the last period (weeks 16-18), it rose significantly. The molar ratio, insulin:glucagon during rehabilitation was calculated according to Anthony \& Faloona (1974) (Fig. 6(b)). It fell a little during each period. The difference became more pronounced following the later period of nutritional rehabilitation but it was never significant except during weeks $1-3$. 

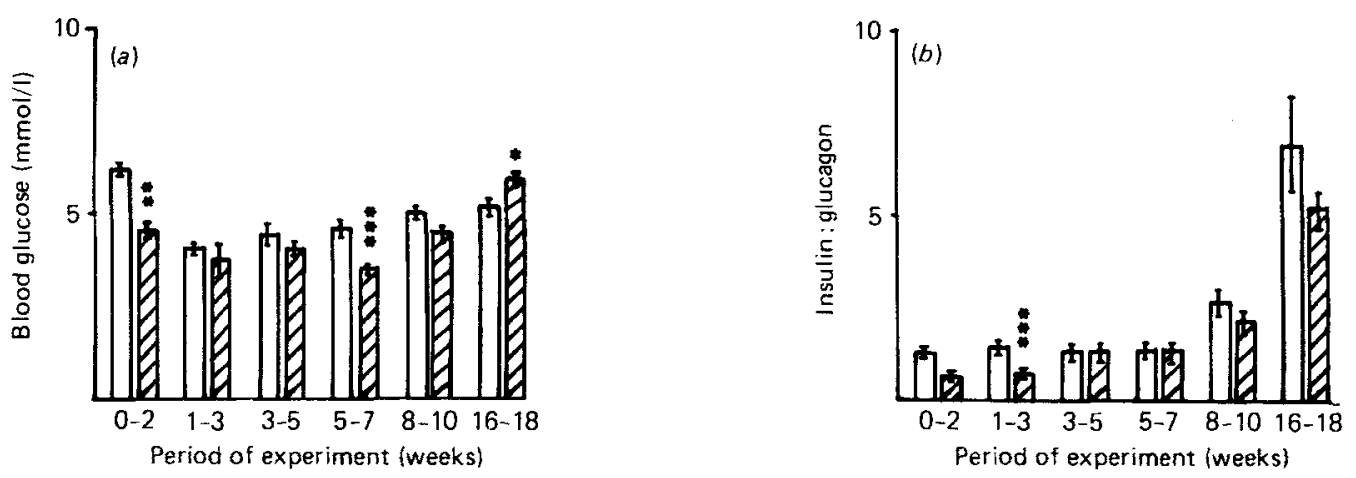

Fig. 6. Changes in $(a)$, blood glucose and (b), molar ratio, insulin: glucagon, of rats born from malnourished mothers and either fed on $50 \mathrm{~g}$ casein-kg diet ad lib. after weaning ( $\square$ ) or rehabilitated

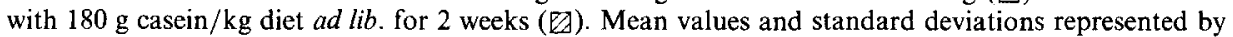
vertical bars. ${ }^{*} P<0.05,{ }^{* *} P<0.01,{ }^{* * *} P<0.001$.

\section{DISCUSSION}

In the present experiment, the effect of a short-term period of rehabilitation after preweaning malnutrition on weight gain and glucose homeostasis was studied. Rats always gained weight without any change in epididymal adipose tissue weight. The effects on plasma constituents were a lower blood glucose and a high plasma glucagon concentration without changes in insulin. They were not different from the first effects of long-term rehabilitation shown in a previous study (Dollet et al. 1987) in which insulin resistance occurred only after 23 weeks of rehabilitation.

Rehabilitation was equally effective at improving food intake and body-weight at all points in the study except during the last period (weeks 16-18). Despite a delayed effect on food intake, there was always 'catch-up' growth, the magnitude of which was constant during the first five rehabilitation periods. This increase in body-weight was not due to adipose tissue which did not increase; it was probably only due to lean body mass, but an effect of water retention cannot be ruled out. The response obtained was different from the effect of rehabilitation only after energy restriction (Ozelci et al. 1978) where adipose tissue weight increased. During the last rehabilitation period, food intake did not increase and the increase in body-weight was delayed. This corresponds to the point when the level of food intake of DR had reached that of normal rats (Beck et al. 1983). Such a time-dependent difference between early and late rehabilitation has been previously described for cellularity of brain and muscle (Okasaki et al. 1981), and for learning ability in rats (Stewart et al. $1980)$.

The variations in IRG levels constituted the most obvious hormonal change induced by short periods of nutritional rehabilitation. During almost all the rehabilitation periods, plasma IRG significantly rose even though IRG pancreatic contents at first fell (weeks 0-2 and 1-3) and then increased. An explanation of this response may be that during the first two periods, RR rats utilized their pancreatic stores of glucagon to increase plasma levels since they are very high after preweaning malnutrition (Dollet et al. 1987). After the 3rd week of postweaning PEM, when pancreatic IRG contents have reached those of normal rats (Dollet et al. 1987), an increase in pancreatic stores was necessary to increase plasma values. Each plasma value after 2 weeks of rehabilitation was similar to that of long-term rehabilitated rats (Dollet et al. 1987) or normal rats (Edozien et al. 1978). The high plasma IRG levels were likely to be related to the fall in blood glucose on rehabilitation to prevent 
hypoglycaemia developing. They could also be due to the enhancement of the protein content of the diet as previously demonstrated by Eisenstein et al. (1974). The absence of a significant increase in adipose-tissue weight throughout the study was probably related to the mobilization of fat stores by the lipolytic action of glucagon.

After each period of rehabilitation, there were no changes in plasma and pancreatic insulin. The 2-week period of rehabilitation was too short to induce any change in IRI levels because 3-5 weeks of rehabilitation are necessary to observe a significant increase in plasma IRI (Dollet et al. 1987). The lack of rapid IRI variations was also probably related to preweaning malnutrition since a 1-week rehabilitation period allows a normalization of plasma insulin in rats fed on either approximately the same low-protein diet as ours (Kababi et al. 1976) or a very-low-protein diet ( 5 g lactalbumin $/ \mathrm{kg}$, Young et al. 1973) after weaning. Despite the lack of change in insulin, rats increased their body-weight as soon as their protein intake increased, i.e. from the 1 st week after the beginning of rehabilitation. This confirms previous results in rats (Nakano \& Hara, 1979) and in children (Heard, 1978). An increased insulin sensitivity of target cells, a phenomenon which has been established in congenitally-malnourished rabbits (Turner, 1978), may explain these fast, positive effects on growth and on the fall in blood glucose despite the high plasma IRG levels.

Thus the effects of rehabilitation on glucose homeostasis depend on the period of rehabilitation: a short rehabilitation leads to high insulin efficiency for growth, and longterm rehabilitation induces insulin resistance (Dollet et al. 1987). This effect is comparable with that observed during the development of experimental obesity (Jeanrenaud et al. 1985; Penicaud et al. 1986) and emphasizes the importance which the effect of an overload of ingested food may have on pancreatic endocrine function.

In conclusion, the present results demonstrate that after preweaning PEM, rats are able, for several weeks, to adapt their pancreatic endocrine function in response to an increase in the protein content of the diet during 'catch-up' growth. These results are very similar to those in malnourished children, where plasma IRI rises slowly during 'catch-up' growth after marasmus (Robinson et al. 1980), but not after kwashiorkor (Persson et al. 1976). However, rehabilitation has to be undertaken as soon as possible to minimize the effects of PEM on the other tissue functions and for better growth.

\section{REFERENCES}

Anthony, L. E. \& Faloona, G. R. (1974). Metabolism 39, 303-306.

Beck, B., Dollet, J. M., Max, J. P. \& Debry, G. (1983). Nutrition Research 3, 743-748.

Dollet, J. M., Beck, B., Max, J. P. \& Debry, G. (1987). British Journal of Nutrition 58, 415-425.

Dollet, J. M., Beck, B., Villaume, Ch., Max, J. P. \& Debry, G. (1985). Journal of Nutrition 115, 1581-1588.

Edozien, J. C., Niehaus, N., Mar, M. H., Makaoui, T. \& Switzer, B. R. (1978). Journal of Nutrition 106 , $1667-1676$.

Edozien, J. C., Rahim Khan, M. A. \& Waslien, C. I. (1976). Diabetes 25, 949-954.

Eisenstein, A. B., Strack, I. \& Steiner, A. (1974). Metabolism 23, 15-23.

Haaga, J., Henrick, C., Test, K. \& Mason, J. (1985). WHO World Health Statistics Quarterly 38, 331 1-347.

Heard, C. R. C. (1978). Diabetes 15, 78-89.

Jeanrenaud, B., Halimi, S. \& Van De Werve, G. (1985). In Diabetes/Metabolism Reviews, vol, 1, pp. 261-291 [De Fronzo, editor]. New York: John Wiley and Sons.

Kababi, J. M., Eisenstein, A. B. \& Strack, I. (1976). Journal of Nutrition 106, 1247-1253.

Nakano, K. \& Hara, H. (1979). Journal of Nutrition 109, 1390-1398.

Okasaki, S., Matsueda, S., Ohnaka, M. \& Niiyama, Y. (1981). Nutrition Reports International 23, $471-484$.

Ozelci, A., Romsos, D. R. \& Leveille, G. A. (1978). Journal of Nutrition 108, 1724-1732.

Penicaud, L., Rohner-Jeanrenaud, F. \& Jeanrenaud, B. (1986). American Journal of Physiology 250, E662-E668.

Persson, B., Habte, D. \& Sterky, G. (1976). Acta Paediatrica Scandinavica 65, 329-336.

Robinson, H. M., Cocks, T., Korr, D. \& Picou, D. (1980). Pediatric Research 14, $28-33$.

Robinson, H. M. \& Picou, D. (1977). Pediatric Research 11, 637-640. 
Rozovski, S. J., Lewis, C. G. \& Cheng, M. (1982). Journal of Nutrition 112, 920-927.

Stewart, R. J. C., Sheppard, H., Preece, R. \& Waterlow, J. C. (1980). British Journal of Nutrition 43, 403-412.

Tafari, N., Naeye, R. L. \& Gobezie, A. (1980). British Journal of Obstetrics and Gynaecology 87, $222-226$.

Turner, M. R. (1978). Proceedings of the Nutrition Society 37, 295-299.

Warren, M. A. \& Bedi, K. S. (1985). Journal of Anatomy 191, 65-75.

Young, N. R., Vilaire, G., Newberne, J. M. \& Wilson, R. B. (1973). Journal of Nutrition 103, 720-729. 